\title{
A Critical Review of Research on Social Networking Sites in Language Teaching and Learning
}

\author{
Osman Solmaz \\ Dicle University, Turkey
}

Received: 16.11.2017

Accepted: 19.06 .2018

Published: 16.07 .2018

\begin{abstract}
The current study aims to present a critical analysis of research on social networking sites (SNSs) in second language teaching and learning (L2TL) context. Twenty-two studies published from 2011 to 2017 were included in the analysis through the selection criteria devised by the researcher. The descriptive analysis reveals that Facebook was the most commonly explored medium, and more than half of the studies featured English language learners in various levels. Following the content analysis of the studies, the emerging aspects of the literature review are treated under five overarching themes: practicing multiple language areas and literacies; authenticity and negotiation of meaning through interaction; development of intercultural competence and socio-pragmatic awareness; membership in L2 communities; and (re)construction of identities. Following an account of pedagogical considerations such as the dynamics of classroom, technical features, and various cultural uses of the SNSs, the study concludes with suggestions and directions for future research in regards to the incorporation of SNSs such as Facebook and Twitter into L2 classrooms.
\end{abstract}

Keywords: Social networking sites; Facebook; Twitter; Language teaching; Social media; Language learning

\section{Introduction}

The emergence and sudden growth of Web 2.0 technologies captured the attention of second language educators and applied linguists among many other professionals. Having played a significant role in the transformation of earlier internet technologies to Web 2.0 (O'Reilly, 2005), social networking phenomenon allowed internet users to extend their face-to-face friendships to online spaces as well as forming new relationship through online social interactions. The advent of these technologies in the broader context of web 2.0 has also created a new mobile and multimodal social space for learners and educators. Given that the biggest social networking site (SNS), Facebook, has about 2.2 billion monthly active users (Facebook, 2018), and social media spans all ages and demographics (Pew Research Center, 2016), the ubiquity of social networking tools necessitate further analysis of their pedagogical value and potential for second language teaching and learning (L2TL).

In previous research, some of the characteristics of SNSs have been praised and found to play an important role in acquisition experiences of language learners. It was highlighted that SNSS provided a virtual environment for the students outside of scheduled class time (e.g., Mills, 2011), and a positive, flexible, and non-threatening space for students to communicate and 
collaborate (Ota, 2011). Furthermore, it is stressed that learners are encouraged to express their opinions more freely in online social spaces in comparison to their interactions in face-toface settings (Harting, 2017). A number of studies also indicated that SNSs created a virtual extension of the face-to-face classroom setting. Mills (2011), for example, observed that such a virtual environment opened up opportunities for learners to engage through exchange of cultural multimedia, interpretive, interpersonal and presentational modes within the social context of their communities. By emphasizing the mobility of these spaces, this type of classroom extension was considered a gathering place where students navigated and interacted in an authentic environment.

Based on such findings, it might be argued that SNSs offer opportunities for learners to enrich their language learning experiences by means of engaging in an informal exploration thanks to the extension of formal lessons into an informal online environment. Moreover, they could conceivably assist individuals with various personality types and learning preferences in experiencing a relatively anxiety-free progression during their L2 learning process.

This study aims to systematically present a comprehensive picture of the research on social networking sites within the context of L2TL. Particularly, the following research questions related to the content of the early research guided the present study:

- What are the emerging themes and issues addressed in the previous scholarship of SNS use in L2TL settings?

- What are the pedagogical considerations for SNS integration into L2TL?

\section{Research Method}

In order to be included in the present study, the articles had to fulfill the following selection criteria which were devised for the literature review:

a) The focus of the research had to be on the use of global or local mainstream social networking sites (SNSs) in the context of $L 2$ teaching and learning.

b) Research had to be published in indexed and peer-reviewed international journals between 2011 and 2017.

The first criterion was chosen to reach studies specifically dealing with SNSs, not social media, which is often regarded as the umbrella term consisting technologies such as instant messaging and social bookmarking. Therefore, studies featuring educational SNSs (e.g., Ning, Edmodo) and/or SNSs developed for language learning (e.g., LiveMocha, Busuu) were excluded from the analysis. In addition to the SNSs, certain studies, which used other web resources (e.g., blogs, e-mails) as data sources as well, were also removed from the list of identified articles during the early stages of the study. The second criterion was selected to access high quality publications. Thus, publications such as book reviews and conference proceedings were not included. Due to the scope of the review, theoretical papers and attitudinal studies were excluded from the analysis as well.

To identify the research conforming to the selection criteria, a systematic search for relevant scholarship was carried out in various databases including ERIC, JSTOR, Web of Science, DOAJ, Science Direct, and Google Scholar. The following key words were searched: social networking 
sites AND "language learning", social networking sites AND "language teaching", social network sites AND "language learning", and social network sites AND "language teaching". Since the term SNS is often interchangeably used with Social Media in the literature, mainstream SNSs such as Facebook, Twitter, and Instagram were also searched in combination with the keywords "language teaching" and "language learning". After this process, the references in the articles matching the criteria were investigated for the purpose of finding additional publications through ancestry approach (See the References to for the list of reviewed articles which are marked with asterisks).

Following the identification of the articles meeting the selection criteria, the previous research was critically analyzed and evaluated by following a comprehensive descriptive approach similar to that used by Hattem and Lomicka (2016). Later, the key themes emerging from the analysis were carefully synthesized to provide an account of the pedagogical affordances, concerns, and considerations of SNS use within L2 teaching and learning (L2TL) context. While descriptive analysis was employed for the identification of research trends such as type of SNSs, the context, the language(s), level of learners, and participant size, content analysis (Glesne, 2010) was adopted for the classification of the research trends across studies.

Overall, the goal was to establish a comprehensive picture and identify common themes across studies on the use of SNS for L2TL purposes and the ways educators can maximize the potential of these interactive spaces in pedagogical contexts.

\section{Results}

In this section, theoretical and methodological trends across the studies are presented along with descriptive statistics including type of SNSs, research sites, language(s) investigated, level of participants, and participant size in the previous scholarship. The review reveals that the studies are theoretically informed by a wide range of frameworks including Byram's Model of Intercultural Communicative Competence (Jin, 2015; Ozdemir, 2017), Language Socialization (Reinhardt \& Zander, 2011), Community of Practice (Mills, 2011), Multiliteracies Approach (Reinhardt \& Ryu, 2013), and Vygostky's Zone of Proximal Development (Ota, 2011). The majority of empirical studies in this particular field of research interpreted their data through the lens of sociocultural and situated learning theories both of which emphasizes the importance of social interaction.

The literature review also reveals that content analysis of the online interactions (e.g., discourse analysis, community of inquiry), interviews (e.g., semi-structured, formal group interviews) surveys, think-aloud sessions, learner self-reports, learner log-sheets of the SNS visits, classroom observation and monitoring, and social network analysis (SNA) are among the some of the methodological/analytical approaches that were taken.

Of the 22 studies that met the selection criteria, an overwhelming majority $(N=16)$ investigated the use of Facebook for L2 teaching and/or learning (Table 1). It is followed by Twitter, arguably the second most popular SNS in the world, which were used in five studies. Popular local SNSs such as Russian VKontakte and Japanese Mixi were also examined in the previous research. Other popular SNSs such as Instagram and Snapchat were not found in any of the studies conforming to the selection criteria. 
Table 1. Type of SNSs $(N=23)$

\begin{tabular}{|c|c|c|}
\hline Type of SNS & $N$ & Studies \\
\hline Facebook & 16 & $\begin{array}{l}\text { Blattner and Fiori (2011); Blattner and Lomicka (2012); Chen } \\
\text { (2013); DePew (2011); Dizon (2016); Harting (2017); Jin } \\
\text { (2015); Liu (2017); Mills (2011); Mitchell (2012); Ota (2011)*; } \\
\text { Ozdemir (2017); Reinhardt and Ryu (2013); Reinhardt and } \\
\text { Zander (2011); Schreiber (2015); Vikneswaran \& Krish (2016) }\end{array}$ \\
\hline Twitter & 5 & $\begin{array}{l}\text { Fouz-González (2017); Hattem (2014); Lomicka and Lord } \\
\text { (2012); Mompean, and Fouz- González (2016); Solmaz (2017) }\end{array}$ \\
\hline Local SNSs (VKontakte, Mixi) & 2 & Klimanova and Dembovskaya (2013); Ota (2011)* \\
\hline
\end{tabular}

* The study features multiple SNSs.

More than half of the research was conducted in the United States context ( $N=12)$, which is respectively followed by Japan $(N=2)$ and Spain $(N=2)$. Certain studies featured multiple research sites due to the telecollaborative nature of the pedagogical implementation. While each of the countries such as Korea, Malaysia, Russia, Serbia, Taiwan, and Turkey were represented once, two of the studies were not spatially-bound as they specifically targeted online context and the medium (Table 2).

It was observed that English language $(N=13)$ dominated the scholarship since more than half of the studies investigated the use of SNSs in teaching English as a foreign/second language. The studies also examined French $(N=3)$ and Spanish $(N=2)$ language learning, while Mandarin, German, Russian, Japanese, and Korean learners were included as well (Table 3).

Table 2. The Context of the Studies $(N=24)$

\begin{tabular}{|c|c|c|}
\hline The Country & $N$ & Studies \\
\hline The United States & 12 & $\begin{array}{l}\text { Blattner and Fiori (2011); Blattner and Lomicka (2012); Chen } \\
\text { (2013); DePew (2011); Hattem (2014); Jin (2015)*; } \\
\text { Klimanova and Dembovskaya (2013)*; Lomicka and Lord } \\
\text { (2012); Mills (2011); Mitchell (2012); Reinhardt and Ryu } \\
\text { (2013); Reinhardt and Zander (2011) }\end{array}$ \\
\hline Japan & 2 & Dizon (2016); Harting (2017) \\
\hline Spain & 2 & $\begin{array}{l}\text { Fouz-González (2017); Mompean, and Fouz- González } \\
\text { (2016) }\end{array}$ \\
\hline $\begin{array}{l}\text { Other countries (Korea, } \\
\text { Russia, Taiwan, Turkey, } \\
\text { Serbia, Malaysia) }\end{array}$ & 6 & $\begin{array}{l}\text { Jin }(2015)^{*} ; \text { Klimanova and Dembovskaya }(2013)^{*} \text {; Liu } \\
\text { (2017); Ozdemir (2017); Schreiber (2015); Vikneswaran \& } \\
\text { Krish (2016) }\end{array}$ \\
\hline Non-geo-based (Web only) & 2 & Ota (2011); Solmaz (2017) \\
\hline
\end{tabular}

* The studies with multiple research sites. 
Table 3. Language(s) Investigated $(N=24)$

\begin{tabular}{|c|c|c|}
\hline Language & $N$ & Studies \\
\hline English & 13 & $\begin{array}{l}\text { Chen (2013)*; DePew (2011); Dizon (2016); Fouz-González } \\
\text { (2017); Hattem (2014); Jin (2015); Liu (2017); Mitchell } \\
\text { (2012) Mompean, and Fouz- González (2016); Ozdemir } \\
\text { (2017); Reinhardt and Zander (2011); Schreiber (2015)*; } \\
\text { Vikneswaran \& Krish (2016) }\end{array}$ \\
\hline French & 3 & $\begin{array}{l}\text { Blattner and Lomicka (2012); Lomicka and Lord (2012); Mills } \\
\text { (2011) }\end{array}$ \\
\hline Spanish & 2 & Blattner and Fiori (2011); Solmaz (2017) \\
\hline $\begin{array}{l}\text { Other languages (Mandarin, } \\
\text { German, Russian, Japanese, } \\
\text { Korean, Serbian) }\end{array}$ & 6 & $\begin{array}{l}\text { Chen (2013)*; Harting (2017); Klimanova and Dembovskaya } \\
\text { (2013); Ota (2011); Reinhardt and Ryu (2013); Schreiber } \\
\text { (2015)* }\end{array}$ \\
\hline
\end{tabular}

* These studies examine multiple languages.

There was a relative balance across the distribution of the studies according to the school levels of the participants. Students with Elementary and Pre-Intermediate levels were included in four studies, while participants with Advanced levels were also featured in four of the analyzed studies. Six of the studies featured learners with multi-levels, and eight studies were conducted at the Intermediate and Upper-Intermediate levels (Table 4). The sample size of majority of these studies $(N=13)$ was 15 or less, while six studies used sample sizes between 16-40, and three of them had 41 participants and more (Table 5).

Table 4. The School Levels of the Participants $(N=22)$

\begin{tabular}{lll}
\hline Level & $N$ & Studies \\
\hline $\begin{array}{l}\text { Elementary, Pre- } \\
\text { Intermediate (A1-A2*) }\end{array}$ & 4 & $\begin{array}{l}\text { Harting (2017); Reinhardt and Ryu (2013); Solmaz (2017); } \\
\text { Vikneswaran \& Krish (2016) } \\
\text { Blattner and Fiori (2011); Blattner and Lomicka (2012); } \\
\text { Intermediate, Upper- }\end{array}$ \\
Intermediate (B1-B2*) & 8 & $\begin{array}{l}\text { Fouz-González (2017); Jin (2015); Lomicka and Lord (2012); } \\
\text { Mills (2011); Mompean, and Fouz- González (2016); } \\
\text { Reinhardt and Zander (2011) }\end{array}$ \\
Advanced (C1-C2*) & 4 & $\begin{array}{l}\text { Chen (2013); Hattem (2014); Ozdemir (2017); Schreiber } \\
(2015) \\
\text { DePew (2011); Dizon (2016); Klimanova and Dembovskaya } \\
\text { (2013); Liu (2017); Mitchell (2012); Ota (2011) }\end{array}$ \\
\hline
\end{tabular}

* Corresponding levels in Common European Framework of Reference (CEFR) 
Table 5. Sample Sizes of Studies $(N=22)$

\begin{tabular}{|c|c|c|}
\hline Size & $N$ & Studies \\
\hline 5 or less & 5 & $\begin{array}{l}\text { Chen (2013); DePew (2011); Hattem (2014); Solmaz (2017) } \\
\text { Schreiber (2015) }\end{array}$ \\
\hline $6-15$ & 8 & $\begin{array}{l}\text { Blattner and Fiori (2011); Harting (2017); Lomicka and Lord } \\
\text { (2012); Mitchell (2012); Ota (2011); Reinhardt and Ryu } \\
\text { (2013); Reinhardt and Zander (2011); Vikneswaran \& Krish } \\
\text { (2016) }\end{array}$ \\
\hline $16-40$ & 6 & $\begin{array}{l}\text { Blattner and Lomicka (2012); Dizon (2016); Liu (2017); Mills } \\
\text { (2011); Mompean, and Fouz- González (2016); Ozdemir } \\
\text { (2017) }\end{array}$ \\
\hline $41+$ & 3 & $\begin{array}{l}\text { Fouz-González (2017); Jin (2015); Klimanova and } \\
\text { Dembovskaya (2013) }\end{array}$ \\
\hline
\end{tabular}

\section{Discussion}

The analysis of the previous research yielded multiple categories surrounding $L 2$ teaching and learning process in SNS contexts. Following the re-examination of these categories, some of them were classified into stand-alone themes since they were more prominent and included sub-categories that were not recurring in multiple studies. Each of the following themes is presented and discussed in the next section:

- Practicing multiple language areas and literacies

- Authenticity and negotiation of meaning through interaction

- The development of intercultural competence and socio-pragmatic awareness

- Membership in L2 communities

- $\quad(\mathrm{Re})$ construction of identities

\section{Theme 1: Practicing Multiple Language Areas and Literacies}

The value of SNSs as a general resource to create new avenues for practicing a multitude of language areas and literacies is dominantly present in the literature. Presenting opportunities for meaningfully embedded interaction with others, SNS use is viewed as a socio-literacy practice (Reinhardt \& Ryu, 2013), which entails the participation of individuals in their respective communities through the demonstration of their language skills. The previous research supports the idea that SNS use contributes to the development of language areas both in general and the specific aspects. For example, multi-level ESOL students in Mitchell (2012) reported improving their English ability through Facebook and the researcher noted that this was as a result of the site giving learners a clear goal for their language use. While the participants in this small-scale qualitative study joined Facebook for various reasons, the medium assisted them in being exposed to target language content as well as in increasing their input in English. DePew (2011) mentioned that developing writing skills of learners might be connected with the fact that individuals are aware of real-world consequences of their products (i.e., audience awareness). He further found that multilingual writers could respond to communicative situations in rhetorically complex ways. 
The writing development of students through SNS use has been empirically investigated in terms of lexical richness, writing fluency, and grammatical accuracy as well. Dizon (2016), for instance, compared L2 English writing improvements of $30 \mathrm{EFL}$ students by their writing with paper-and-pencil (the control group) and Facebook (the experimental group). Although no significant improvements regarding lexical richness and grammatical accuracy were present, Japanese EFL learners in the experimental group were found to make meaningful progress on each assessment test in terms of writing fluency while there was no significant improvements in the control group. This finding conforms to the research conducted by Vikneswaran and Krish (2016), who found that Facebook promoted writing fluency of Chinese ESL students largely thanks to the contributions and discussions of ideas on the private group page. However, the study also demonstrated that the participants experienced writing challenges particularly in vocabulary and grammar. Similarly, Harting (2017) observed that preintermediate German learners in Japan mostly relied on the speech acts and expressions presented in pre-writing activities rather than incorporating the structures they encountered while engaging in authentic interactions with $L 2$ speakers.

Aside from writing literacies, a relatively new yet much-needed strand of SNS research has emerged around improving listening skills of L2 learners through SNS use. To illustrate, Mompean and Fouz-González (2016) examined the role of Twitter on Spanish EFL students' pronunciation skills and observed that sharing a number of tweets featuring pronunciation of pre-selected words had a beneficial effect on learners' pronunciation of the target words. Later, Fouz-González (2017) further investigated pronunciation instruction on Twitter and found results displaying significant improvements on the pronunciation of the target features in the study's experimental group compared to the control group. Both of the studies may help pave the way for expanding this small strand of research in multiple contexts across various learner groups and establishing new directions for other language areas and literacies such as speaking and reading.

\section{Theme 2: Authenticity and Negotiation of Meaning through Interaction}

One of the reoccurring themes in social networking studies within L2TL context is centralized around authenticity and interaction. SNSs were shown to create spaces for learners to be exposed to authentic input in an informal context with opportunities for authentic output. It was also reported that it afforded a rich environment for students to access native speakers and target culture while having a chance of interactions for the negotiation of meaning.

A notable number of the research pointed out that SNS offered convenient possibilities for learners to engage in, learn about, and make observations regarding the target language and culture in SNS spaces. McBride (2009) accurately observed that learners could display more authentic behaviors by means of social interaction with native speakers in these spaces, while Ota (2011) expressed that content in SNSs consisted of real questions, requirements, and comments from the members, thus generating more natural interaction in contrast to artificial material in text books. In an empirical telecollaboration study designed by Jin (2015), Korean EFL learners, whom have limited opportunities to have direct contact with the native speakers and the target culture, successfully engaged in communication with the target language speakers and demonstrated their intercultural competence in a purposefully created Facebook space. Overall, it is argued that SNSs enable learners to have access to authentic input and naturally flowing conversational speech by increasing the potential of students to take control of their own learning and thus developing learner autonomy (Solmaz, 2017). 
The universality of SNSs also meant that language learners could easily contact with native speakers (NSs) all over the world. This particular affordance of SNS was raised by a number of scholars including Jin (2015) and Harting (2017), whose research illustrated that communication with native speakers was a viable option regardless of students' geographical location. In a small case study by Hattem (2014), the evidence of negotiation of meaning was found among three Intensive Academic English Program students who practiced their grammar skills through frequent participation on Twitter. In a similar vein, Liu (2017) specifically examined the negotiated interaction between non-native speakers of English and between native and non-natives. The study revealed examples of negotiation for meaning among all groups although it was reported that such instances were more likely to occur across nonnative speakers with high-proficiency level. Finally, Solmaz (2017) documented his autonomous L2 learning experiences in a year-long auto-ethnographic study, in which he concluded that effective use of hashtags in microblogging contexts like Twitter allowed L2 learners to reach target language users and engage in a meaningful interaction with them. In regards to the target culture, it was acknowledged in the past research that SNSs enabled learners to interact with, learn and observe the L2 culture (Mitchell, 2012), better comprehend the interrelationship between language and culture (Lomicka \& Lord, 2012), and develop their intercultural understanding (Jin, 2015).

\section{Theme 3: Development of Intercultural Competence and Socio-Pragmatic Awareness}

Previous studies suggest that SNSs may play a role in assisting L2 learners in developing intercultural competence and socio-pragmatic skills in socio-interactive online environments. The presence and the multimodality of the various versions of target language elements in these spaces might indeed prove to be beneficial for individuals to both increase their sociocultural and pragmatic awareness and facilitate their adjustment into the communities there. In a recent study, Jin (2015) examined the role of Facebook for Korean EFL students' intercultural learning through a telecollaboration project between U.S. and Korea. The findings indicated that learners successfully demonstrated the components of intercultural competence while participating in interactions with the target culture speakers. Even though the study did not explore the experiences of American students, it provided valuable insights into the ways SNSs can be used as mediums for telecollaboration projects. The function of SNSs as spaces for intercultural instruction has been compared with traditional teaching environment as well. In his recent research, Ozdemir (2017) analyzed how intercultural instruction on Facebook and in face-to-face teaching context affected EFL learners' intercultural communicative effectiveness. Following a mixed-methods approach, he found that the discussion on Facebook group was significantly more successful than the discussion group in the class. This might confirm the idea that discussing with people of different cultures on SNSs is more efficient on the intercultural understanding of learners compared to that of the in-class discussions.

Another strand of the research is concentrated on the development of pragmatic skills, which are considered fundamental to L2 development (Mills, 2011). Highlighting the value of individuals' engagement within L2 communities in socio-pragmatically appropriate ways for a successful language learning experience, previous research approached SNSs as spaces where pragmatic sources are accessible unlike textbooks which tend to include inauthentic language samples and may not be the most reliable pragmatic resource (Blattner \& Fiori, 2011). For example, investigating Facebook Groups for learning Spanish, Blattner and Fiori (2011) 
observed that the language varieties displayed by group members exposed learners to linguistic varieties. They suggested that Facebook could bridge the gap especially when textbooks cannot meet the socio-pragmatic demands of learners. Supporting this idea, the research showed that Facebook project enabled L2 learners to reconfigure standard communication patterns in French (Mills, 2011), to effectively recognize similarities and differences of a variety of speech acts in Spanish (Blattner \& Fiori, 2011), and to have the potential to promote individuals to develop noticing cultural and linguistic references (Solmaz, 2017).

In line with the findings above, the analysis of language used by forum and social members enhanced socio-pragmatic awareness of French language learners (Blattner \& Lomicka, 2012). Pointing out the differences between standard writing contexts and unconventional sites like SNSs, DePew (2011) praised SNSs for not imposing monolingual norms and structures unlike the developmental-writing courses. Finally, Reinhardt and Ryu (2013) found evidence for socio-pragmatic development of Korean L2 learners through the activities designed in accordance with Bridging Activities Framework (Thorne \& Reinhardt, 2008). They concluded that SNSs could function "both as arenas for experiencing the socio-pragmatics of language firsthand, and as texts for analyzing the socio-grammatical instantiations of those uses" (p. 31). Overall, it can be concluded that the integration of pre-planned and designed SNS-mediated activities could positively contribute to intercultural and socio-pragmatic development of L2 learners.

\section{Theme 4: Membership in L2 Communities}

A high level of interaction in social networking spaces was naturally resulted in the exploration of online communities in L2TL context. Given that being a member of a group has a meaningful effect on the way relationships are established and maintained (Donath \& Boyd, 2004), researchers analyzed the dynamics of online L2 communities that were formed. It was generally indicated that online communities positively contributed to the L2 learning and teaching experiences (e.g., Lomicka \& Lord, 2012; Mitchell, 2012). Investigating how Japanese language learning groups on Facebook and Mixi, a Japanese SNS, provided a space for learners, Ota (2011) noted that members primarily used SNSs to post event information, ask about schedules of other members, comment about events, and share event pictures and videos. Similarly, multimodal elements played a role in information exchange of members in Klimanova and Dembovskaya's (2013) study of vKontake as well. The researchers observed that digital artifacts such as photos, video posts, layout designs, and music preferences were consciously and strategically selected. They also identified that the language of emoticons and punctuation signs were some of the sources of social information among the members of telecollaboration group. This finding was also present in the research conducted by Reinhardt and Ryu (2013), who observed that learners used Korean emoticons especially when honorifics would have been more appropriate, which signified that Korean learners were aware of the affordances of the medium (i.e., Facebook).

With respect to community building and maintenance in social networking environments, it was emphasized that the nature of SNSs was often rooted in community formation and maintenance, thus affording constructive pedagogical experiences without being concerned about privacy and safety thanks to applications such as Groups on Facebook (Blattner \& Fiori, 2011). Twitter was also found to facilitate community building and the development of a sense of trust in an interactive way (Lomicka \& Lord, 2012). Collaboration in SNS also enabled 
learners to foster relationships with other community members leading to a positive classroom climate (Harting, 2017), and to express themselves in new and different ways and to have an opportunity for membership in the L2 community (Solmaz, 2017). Finally, in a case study by Hattem (2014), three Intensive Academic English students formed and maintained their own community through language play in frequent interactions with one another. The study demonstrated that community construction in SNSs extended opportunities for learners to take risks, increase motivation, and finally established an affinity space cultivating a sense of belonging.

\section{Theme 5: (Re)Construction of Identities}

Communications and performances of language learners in semiotically-mediated online spaces leading to construction of complex and dynamic identities merit a special attention. Identity performance and self-presentation are often experienced in SNSs mostly because such virtual worlds enable learners to experiment with multiple identities more safely as they do not occur in a monolithic real world (McBride, 2009). Interaction practices of learners sustain the process of adopting new, dynamic, and shifting identities through language for them (Mills, 2011). Going beyond whether identities can be constructed in SNS, the research (e.g., Chen, 2013; Klimanova \& Dembovskaya, 2013) often deals with the function of social networking spaces in the (re)construction of learner identities, how identities are transformed in these sites, and what kind of pedagogical potential they hold for L2TL context.

The investigation of the question how SNSs provided an environment for the construction of dynamic language learner identities revealed that social, technical and multimodal characteristics of these spaces were effective. It was constantly reported that identities were established mainly through the communication taking place on personal profiles (Reinhardt \& Zander, 2011). Profile pages are generally considered ideal places for identity performances because users can manipulate and design their profiles. Indeed, it was shown in the previous works that the profiles were often manipulated and/or designed with semiotic resources including texts, photos, videos, hyperlinks, and linguistic elements (Chen, 2013). For instance, learners sometimes harnessed their multilingual repertoire while presenting themselves to different audiences (DePew, 2011), while other individuals such as Aleksandr preferred to achieve that richness through the assistance of multimodality and translingualism (i.e., not necessarily tying his linguistic identities to individual languages).

It was also revealed that the identity (re)construction was a dynamic process which featured multiple and developmental identities being formed by multilingual writers (Schreiber, 2015). To illustrate, Aleksandr in Schreiber (2015), indexed himself as a member of a global hip-hop community while displaying performances that project his local identity in Serbian context. However, as mentioned by Reinhardt and Zander (2011), SNSs allowed L2 learners abroad to develop new identities and integrate them with the old ones yet some students could find such new identities unsettling and against their home discourses. The function of participation in local and global networks while managing an impression in these spaces is a key factor to take into account as well. Analyzing the discursive establishment of Russian learners' online identities, Klimanova and Dembovskaya (2013) observed that learners redefined their identities by contesting presuppositions or developed further attributes throughout the conversation with project partners. Naming the L2 speaker identity as a "dynamic identity-inthe-making" (p. 82), they showed the examples of how students learned to claim and withdraw their identities while engaging in conversation with fellow community members. 
To recapitulate, it is concluded that SNSs created a hybrid space for learners where they could both navigate through a multicultural environment and (re)construct identities while interacting with other members of community in semiotically rich social networking activities. Developing these types of resources and integrating them into L2 classrooms could very well maximize the affordances of SNSs.

Overall, this particular review of literature treated emerging aspects of the literature under major themes including language development, negotiation of meaning, community formation, intercultural competence, socio-pragmatic awareness, and identity construction, all of which presented various affordances for incorporation of SNSs in L2TL contexts. (See Table 6 below for the highlighted affordances discussed in this review).

Table 6. Highlighted Affordances for Each Theme Emerging from the Literature Review

\begin{tabular}{|c|c|}
\hline Theme & Highlighted Affordances \\
\hline $\begin{array}{l}\text { Practicing Multiple } \\
\text { Language Areas and } \\
\text { Literacies }\end{array}$ & $\begin{array}{l}\text { - Contribution to developing language skills and literacies } \\
\text { - Learners being more aware of real-world consequences of their works } \\
\text { - An environment to practice multiple language areas (mainly writing, } \\
\text { reading, and pronunciation) } \\
\text { - Potential improvement in certain areas such as pronunciation } \\
\text { - Increase in the amount and frequency of production and reception of } \\
\text { target language }\end{array}$ \\
\hline $\begin{array}{l}\text { Authenticity and } \\
\text { Negotiation of Meaning } \\
\text { through Interaction }\end{array}$ & $\begin{array}{l}\text { - An interactive environment to access native speakers and target } \\
\text { culture } \\
\text { - A space to be exposed to authentic input in an informal context } \\
\text { - Opportunities for interactions for the negotiation of meaning with } \\
\text { target language users } \\
\text { - A better comprehension of the interrelationship between L2 and } \\
\text { target culture }\end{array}$ \\
\hline $\begin{array}{l}\text { Development of } \\
\text { Intercultural } \\
\text { Competence and Socio- } \\
\text { Pragmatic Awareness }\end{array}$ & $\begin{array}{l}\text { - Learners being exposed to various linguistic varieties } \\
\text { - Opportunities to reconfigure standard and non-standard } \\
\text { communication patterns } \\
\text { - Recognition of similarities and differences of speech/writing styles } \\
\text { - Development in noticing cultural and linguistic references } \\
\text { - Increase in socio-pragmatic awareness } \\
\text { - Monolingual norms and structures not being imposed on individuals }\end{array}$ \\
\hline $\begin{array}{l}\text { Membership in L2 } \\
\text { Communities }\end{array}$ & $\begin{array}{l}\text { - Cultivation of a sense of trust and belonging in a learning community } \\
\text { - Facilitation of community building in an interactive way } \\
\text { - Opportunities for collaborative learning } \\
\text { - Displaying membership through digital multimodal artifacts (e.g., } \\
\text { photos, videos, designs of the profiles) } \\
\text { - An interactive space for back-channeling (i.e., constantly being in touch } \\
\text { for posts and class-related information, announcements, events etc.) }\end{array}$ \\
\hline $\begin{array}{l}\text { (Re)Construction of } \\
\text { Identities }\end{array}$ & $\begin{array}{l}\text { - Assisting learners in the process of adopting new, dynamic, and } \\
\text { shifting identities through language } \\
\text { - Establishment and projection of identities through profiles and } \\
\text { semiotic resources including texts, photos, videos, and hyperlinks } \\
\text { - Formation of multiple and development identities by multilingual } \\
\text { individuals } \\
\text { - The use of multilingual repertoires to present oneself to multiple } \\
\text { audiences in online social networks }\end{array}$ \\
\hline
\end{tabular}




\section{Concerns and Pedagogical Considerations}

As one of the goals of the present study is to provide an account to bridge a potential disconnection between research and practice, the ways L2 educators can maximize the affordances of SNS use and minimize the concerns raised by the literature are discussed in this section.

Given that research indicates the potential contribution of SNSs to the development of learners' socio-pragmatic awareness and competence, it is important that L2 educators harness this particular aspect of SNS by introducing culture-specific conversations and discourse styles and raise awareness both in the sense of socio-pragmatic competence and SNS use. One way for learners to accomplish that is to include less formal variants of grammatical and lexical information to develop both socio-pragmatic and genre awareness (Blattner \& Lomicka, 2012). In terms of practicing sociolinguistic competence and developing SNS awareness, teachers can make use of the utterances from authentic discourses and discuss them in classroom setting. Bridging Activities Framework (Thorne \& Reinhardt, 2008) may be exploited for a more systematic approach to benefit from the online resources as it legitimizes and values the use of vernacular language present in online settings like SNS as L2 learning resource (Reinhardt \& Ryu, 2013). According to the framework, analysis of studentselected or student-created situated texts accompanied by the educator's guidance play a major role in the development of both socio-pragmatic and SNS use awareness. Hence, bridging activities can assist $\mathrm{L} 2$ educators for maximizing the pedagogical affordances of sociointeractive mediated online environments.

Commercialization of technology-driven language learning software programs can impress consumers irrespective of its theoretical base and content. Kern, Ware, and Warschauer (2008) warned that educators should be critical consumers while learners need to become critical evaluators of sources. Teachers should help learners to become more critical in their use of such technologies including SNS. This is one of the responsibilities of L2 educators who should incorporate new media literacies into the classroom by considering the needs and interests of learners.

Another issue that has to be taken into account is the culture of use (Thorne, 2003), the way a particular technology is adopted and used in a group, geographical area, or country. Due to 'the culture of use', the integration of a SNS into an L2 classroom requires a careful understanding of the culture of the use in $\mathrm{L} 2$ communities especially if learners are expected to interact with native speakers. Furthermore, students might not be enthusiastic enough about SNS-mediated environment if it is unfamiliar to them or no training of SNS use is provided (McBride, 2009).

The personality of the students, technical features of the medium, and classroom dynamics also need to be considered for selecting a social networking environment for pedagogical purposes. While L2 educator needs to be familiar with interests and potential attitudes of learners, teachers should also be aware of the differences in being a teacher in a physical context to being a member on the site under equal terms. McBride (2009) warned that relationships among students could affect the outcome and it may even feel forced and false especially in cases when some students may not want to be each other's' friends. In terms of the technical aspects, it is suggested that particular features of the medium (e.g., video call) should be carefully taken into account during the design process of activities as the level of 
learners could affect their participation in various activities. Finally it is recommended that students are not required to share their real identities as they may feel forced, thus "negating any motivational benefits that bridging authentic everyday use into the classroom might bring" (Reinhardt \& Zander, 2011, p. 333). Despite of all the affordances of SNS, it is recommended that the pedagogy itself rather than the technological medium should empower the language learning activities.

\section{Recommendations for Future Research}

Informed by the recent literature on the examination of SNS use in L2TL context, a number of recommendations is made in order to fill some of the gaps or contribute to the ongoing academic conversation in this growing scholarship.

Given that the devoted time to the examination of SNS phenomenon in L2TL has been limited to one academic semester or often less, longitudinal studies need to be conducted to have a relatively broader picture. Since it was reported that initial motivation gradually declined throughout the learning processes, similar research could examine to what extent novelty of the medium itself and the SNS activities might affect this process. In regards to theoretical and methodological directions, it can be suggested that socioculturally-oriented frameworks such as Language Socialization and Community of Practice are likely to continue guiding the research in combination with alternative methodologies including diary studies, online ethnographic field work, and social network analysis. Existing scholarship of telecollaboration in broader context of computer-mediated communications (CMC) could also inform similar studies within a SNS environment.

Pedagogical and technical usability of SNSs could be investigated in educational contexts, or future research may be concentrated on one particular element of the site as in Zourou and Loiseau's (2013) work. Underexplored areas such as learners' online literacy practices, speaking and listening skills, assessment and evaluation also deserve more attention. The investigation of multiple identities in informal online study space as part of a classroom should also greatly inform the identity research in online contexts. As suggested by Harting (2017), the role of students' personal and teacher-assigned SNS interactions on their L2 learning needs to be further investigated as well. Finally, less commonly taught languages, local SNSs, underexplored SNSs such as Instagram and Snapchat as well as specific features of SNSs such as hashtags, 'stories` are among the areas which are to be empirically examined in detail.

\section{Concluding Remarks}

The present study investigated the pedagogical affordances and considerations of Social Networking Sites (SNSs) in second language learning and teaching (L2TL) context. The first research questions was about the themes and issues addressed in the previous scholarship. The research showed that mobility, multimodality, and sociality of these sites afforded an authentic space where learners could negotiate meaning through interaction, practice various language skills, become content creators, develop their intercultural understanding and sociopragmatic awareness, socialize into L2 communities, and construct multiple dynamic identities. For the second research question regarding the pedagogical considerations for integrating SNSs into L2TLs, it is suggested that language educators create pedagogically appropriate ways after considering a multitude of issues such as technical features of the medium, 'culture of 
use', and classroom dynamics. Overall, it is concluded that SNSs indeed hold great potential for L2TL and further research should be conducted for further understanding of the phenomenon.

\section{References}

Articles marked with an asterisk $\left({ }^{*}\right)$ were analyzed in this study.

*Blattner, G. \& Fiori, M. (2011). Virtual social network communities: An investigation of language learners' development of socio-pragmatic awareness and multiliteracy skills. CALICO Journal, 29(1), 24-43.

*Blattner, G. \& Lomicka, L. (2012). Facebook-ing and the social generation: A new era of language learning. ALSIC 15(1). Retrived on 15 November 2017 from https://journals.openedition.org/alsic/2413

*Chen, H. (2013). Identity practices of multilingual writers in social networking spaces. Language Learning \& Technology, 17(2), 143-170.

*DePew, K. E. (2011). Social Media at Academia's Periphery: Studying Multilingual Developmental Writers' Facebook Composing Strategies. The Reading Matrix, 11(1), 54-75.

*Dizon, G. (2016). A comparative study of Facebook vs. paper-and-pencil writing to improve L2 writing skills. Computer Assisted Language Learning, 29(8), 1249-1258.

Donath, J., \& Boyd, d. (2004). Public displays of connection. BT Technology Journal, 22(4), 7182.

Facebook (2018). Facebook newsroom. Retrieved on 7 May 2018 from http://newsroom.fb.com/company-info/

*Fouz-González, J. (2017). Pronunciation instruction through Twitter: the case of commonly mispronounced words. Computer Assisted Language Learning, 30(7), 631-663.

Glesne, C. (2010). Becoming qualitative researchers ( $4^{\text {th }}$ ed.). Boston, MA: Pearson.

*Harting, A. (2017). Using Facebook to improve L2 German students' socio-pragmatic skills. The EUROCALL Review, 25(1), 26-35.

*Hattem, D. (2014). Microblogging activities: Language play and tool transformation. Language Learning \& Technology, 18(2), 151-174.

Hattem, D. \& Lomicka, L. (2016). What the Tweets say: A critical analysis of Twitter research in language learning from 2009 to 2016. E-Learning and Digital Media, 13(1), 5-23.

*Jin, S. (2015). Using Facebook to promote Korean EFL learners' intercultural competence. Language Learning \& Technology, 19(3), 38-51.

Kern, R., Ware, P., \& Warschauer, M. (2008). Network-based language teaching. In DeusenScholl \& Hornberger (Eds.), Encyclopledia of language and education, 2nd Edition, Vol4: Second and foreign language education (pp. 281-292). New York: Springer.

*Klimanova, L. \& Dembovskaya, S. (2013). L2 Identity, Discourse, and Social Networking in Russian. Language Learning \& Technology, 17(1), 69-88.

*Liu, S. H. (2017). Text-based negotiated interaction of NNS-NNS and NNS-NS dyads on Facebook. ReCALL, 29(3), 294-312. 
*Lomicka, L. \& Lord, G. (2012). A tale of tweets: Analyzing microblogging among language learners. System, 40, 48-63.

McBride, K. (2009). Social networking sites in foreign language classes: Opportunities for recreation. In L. Lomicka \& G. Lord (Eds.), The next generation: Social networking and online collaboration in foreign language learning (pp. 35-58). San Marcos, TX: CALICO.

*Mills, N. (2011). Situated learning through social networking communities: The development of joint enterprise, mutual engagement, and a shared repertoire. CALICO Journal, 28(2), 345-368.

*Mitchell, K. (2012). A Social Tool: Why and how ESOL students use Facebook. CALICO Journal, 29(3), 471-493.

*Mompean, J. A. \& Fouz- González, J. (2016). Twiter-based EFL pronunciation instruction. Language Learning \& Technology, 20(1), 166-190.

O'Reilly, T. (2005). What is Web 2.0? Design patterns and business models for the next generation of software. Retrieved on 8 September 2017 from http://www.oreilly. com/web2/archive/what-is-web-20.html

*Ota, F. (2011). A study of social networking sites for learners of Japanese. New Voices, 4, 144 167.

*Ozdemir, E. (2017). Promoting EFL Learners' intercultural communication effectiveness: a focus on Facebook. Computer Assisted Language Learning, 30(6), 510-528.

Pew Research Center (2016). Social media update 2016. Retrieved on 1 June 2017 from http://www.pewinternet.org/2016/11/11/social-media-update-2016/

*Reinhardt, J. \& Ryu, J. (2013). using social network-mediated bridging activities to develop socio-pragmatic awareness in elementary Korean. International Journal of ComputerAssisted Language Learning and Teaching, 3(3), 18-33.

*Reinhardt, J. \& Zander, V. (2011). Social networking in an intensive english program classroom: A language socialization perspective. CALICO Journal, 28(2), 326-344.

*Schreiber, B. R. (2015). "I am what I am": Multilingual identity and digital translanguaging. Language Learning \& Technology, 19(3), 69-87.

*Solmaz, O. (2017). Autonomous language learning on Twitter: Performing affiliation with target language users through \#hashtags. Journal of Language and Linguistic Studies, 13(2), 204-220.

Thorne, S. (2003). Artifacts and cultures-of-use in intercultural communication. Language Learning \& Technology, 7(2), 38-67.

Thorne, S. \& Reinhardt, J. (2008). 'Bridging activities,' new media literacies and advanced foreign language proficiency. CALICO Journal, 25(3), 558-572.

*Vikneswaran, T. \& Krish, P. (2016). Utilising social networking sites to improve writing: A case study with Chinese students in Malaysia. Technology, Pedagogy and Education, 25(3), 287-300.

Zourou, K. \& Loiseau, M. (2013). Bridging design and language interaction and reuse in Livemocha's Culture section. In M. Lamy \& K. Zourou (Eds.), Social networking for language education (pp. 77-99). Basingstoke, UK: Palgrave Macmillian. 
CONTEMPORARY EDUCATIONAL TECHNOLOGY, 2018, 9(3), 315-330

https://doi.org/10.30935/cet.444120

Correspondence: Osman Solmaz, Ph.D., Instructor, Department of Foreign Languages, Ziya Gokalp Faculty of Education, Dicle University, Diyarbakir, Turkey 